\begin{tabular}{lc|c|c|}
\hline Bentham OPEN & The Open Dentistry Journal \\
\hline CrossMark & Content list available at: www.benthamopen.com/TODENTJ/ \\
\hline
\end{tabular}

\title{
Non-Inflammatory Destructive Periodontal Disease
}

\author{
José Ricardo Kina ${ }^{1, *}$, Thaís Yumi Umeda Suzuki ${ }^{2}$, Eunice Fumico Umeda Kina ${ }^{3}$, Juliana Kina ${ }^{4}$ and \\ Mônica Kina ${ }^{3}$ \\ ${ }^{I}$ Department of Surgery and Integrated Clinic, Araçatuba School of Dentistry, São Paulo State University - UNESP, \\ Araçatuba, SP, Brazil \\ ${ }^{2}$ Department of Dental Materials and Prosthodontics, Araçatuba School of Dentistry, São Paulo State University - \\ UNESP, Araçatuba, SP, Brazil \\ ${ }^{3}$ DDS, Private Practice, Araçatuba, SP, Brazil \\ ${ }^{4}$ Department of Pediatric Dentistry and Public Health, Araçatuba School of Dentistry, São Paulo State University - \\ UNESP, Araçatuba, SP, Brazil
}

\begin{abstract}
:
\section{Background:}

Non-Inflammatory Destructive Periodontal Disease (NIDPD), is a severe destructive periodontal disease, that is characterized by the attachment loss and alveolar bone loss, without signs of the gingival inflammation, and the periodontal pocket development.

\section{Objective:}

Despite the fact that various cases of NIDPD have been reported; their etiology and disease evolution is still indefinite, and therefore, are open for discussion.
\end{abstract}

\section{Method:}

An NIDPD case was studied in order to demonstrate features of the disease, and discuss the possible etiology and treatment.

\section{Results:}

In this clinical case, the etiology of NIDPD seems to be an association of endogenous opportunist bacteria with anatomical aspects, occlusion pattern, emotional stress and mouth breathing condition.

\section{Conclusion:}

In spite of all cases described in the literature are comparable and may have similar etiology as related in this clinical case, additional research is needed to identify and clarify the role of the etiologic factors which determine the disease.

Keywords: Etiologic factors, gingival recession, inflammatory process, non inflammatory destructive periodontal disease.

\section{INTRODUCTION}

Periodontal disease results from the association of the bacteria with many other etiologic factors [1 - 6]. Although, bacteria are a critical etiologic factor that are needed to develop a periodontal disease, bacteria alone are insufficient to induce a periodontal disease; a susceptible host is also required, and the host's susceptibility as local and/or general predisposing risk factors, are important determinants of the disease status [1 - 13]. An accurate diagnosis is often essenti

\footnotetext{
* Address correspondence to this author at the Department of Surgery and Integrated Clinic - UNESP Rua José Bonifácio, 1193 Araçatuba 16015-050 SP Brazil; Tel/Fax: 5518 3636-3200; E-mail: kinajr@hotmail.com
} 
-al in developing a predictable and suitable treatment plan, which when executed, gives a guide to the resolution of the periodontal disease's activity $[14,15]$. Majority of all forms of periodontal diseases, are considered as microorganisms-induced dependent, which promotes a defensive inflammatory host's response against the bacteria and noxious materials from the bacterial plaque [1 - 6, 10 - 13, 16 - 18]. The inflammatory process inactivates the bacteria, but produces the liberation of bacterial and neutrophils products such as enzymes, which induce periodontal tissue destruction by lytic activities [12, 13, 16 - 18]. Therefore, the characteristics of the most common periodontal disease are: presence of gingival inflammation, ulceration of the junctional epithelium, loss of connective tissue and alveolar bone, causing apical migration of the junctional epithelium [19]. In majority of the patients suffering from periodontal disease, the consequence is the development of periodontal pocket [13, 19]. However not all types of periodontal disease seem to be periodontopathogenic bacteria dependent, and not all are distinguished by evident inflammatory process, and periodontal tissue destruction associated with periodontal pocket formation and progressive deepening [20, 21]. Non-Inflammatory Destructive Periodontal Disease (NIDPD), is a severe destructive periodontal disease, which is characterized by periodontal attachment loss, alveolar bone loss, generalized gingival recession without pathognomonic sign of inflammation, and periodontal pocket development [20,21]. Conventional periodontal therapy and antimicrobial therapy are ineffective, in preventing further progression of the disease [20]. Despite the fact that noninflammatory destructive periodontal disease has been reported in the literature, its etiology, progression and treatment, are still indefinite and therefore, are open to discussion $[20,21]$. In this paper, we presented a case that demonstrated the features of the disease and discussed the probable etiology and possible therapy.
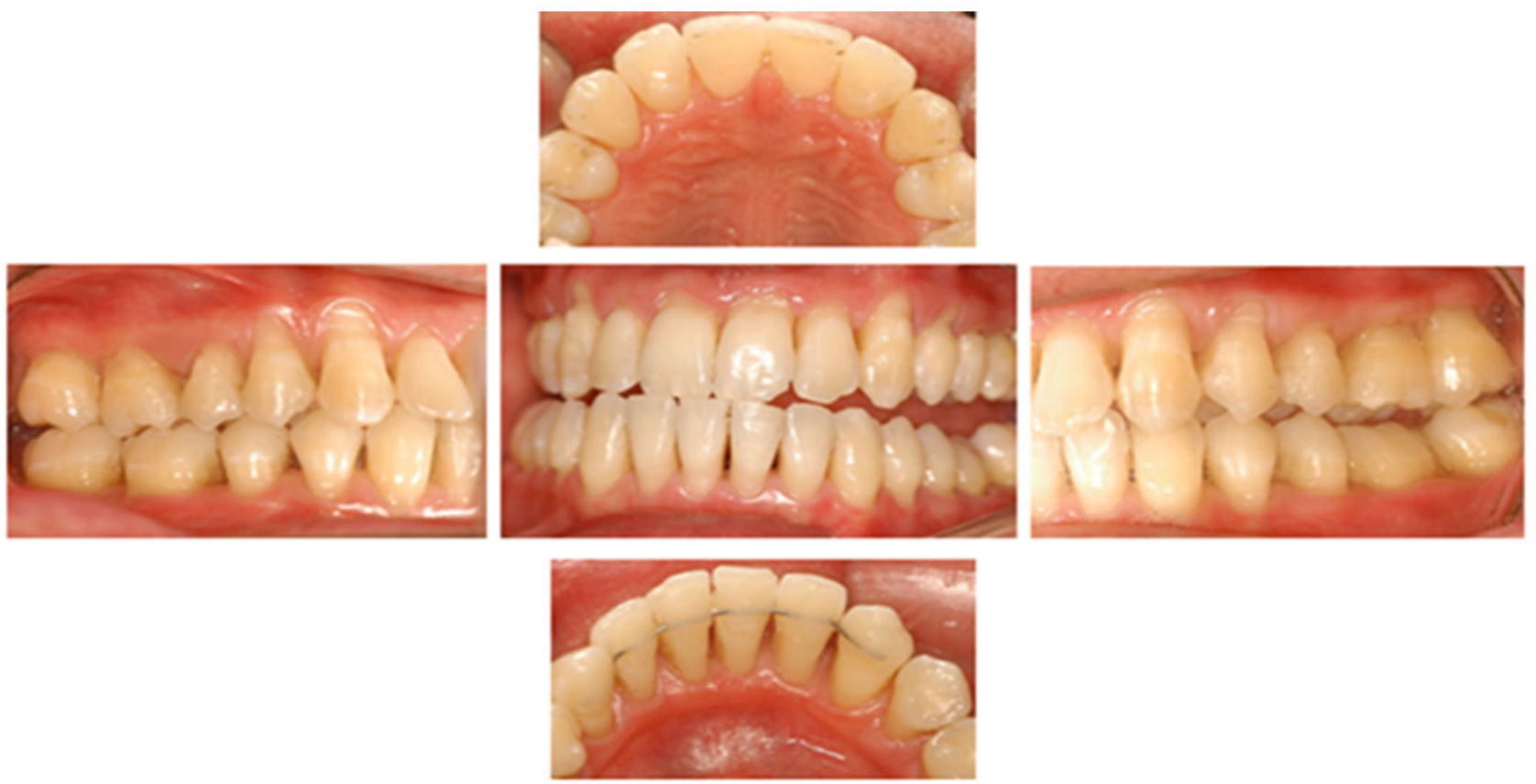

Fig. (1). Clinical features of patient.

\section{CASE REPORT}

The patient, a 31 year old healthy male Caucasian, who was an anesthesiologist, from São Paulo in Brazil, identified symptoms like gingival recession, dentine hypersensitivity and mobility in teeth 31 and 41 , greater than its original physiology, went to a general dental practitioner for dental health care. The professional carried out an extra-coronal splinting in the lower anterior teeth, and gave him a referral to consult the Periodontology Department of the UNESPAraçatuba, São Paulo, Brazil. In the anamnesis questionnaire, the patient informed that there was no previous specific periodontal treatment, neither was he taking any medication for at least 3 months prior to this study, and denied any preexisting systemic conditions or significant history of harmful habits.

However, the patient revealed a nasal obstruction and chronic mouth breathing condition, which induced an altered maxillary arch development with a high narrow vault. Clinical and radiographic assessments were obtained, with a similar protocol used by Page et al. (2002) [20] and Repeke et al. (2012) [21]. The patient also submitted to standard 
protocols, for the evaluation of the hematological and endocrine markers, as used by Repeke et al. (2012) [21]. Microbiology tests were carried out, by employing the methodology applied by Page et al. (2002) [21]. Concerning the dental occlusion conditions, a significant deflective premature contact in the centric relation was verified. The premature contact deflected the mandible forward and away from the centric relation, to the maximum intercuspation causing an effective and deleterious contact in the anterior teeth.

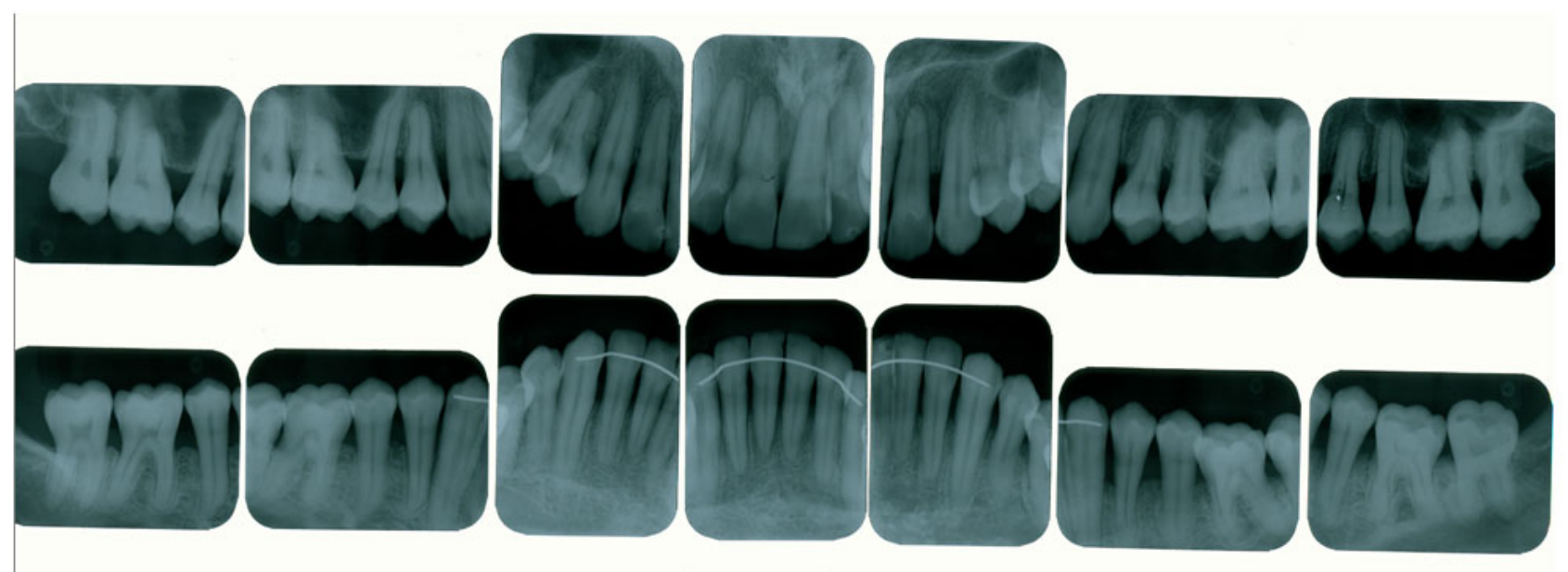

Fig. (2). Radiographic features showing horizontal alveolar bone loss.

The posterior premature contact was, adjusted in the centric relation, in order to stabilize the mandible, and to eliminate a deleterious contact in the anterior teeth. No eccentric movements were defective. The patient also had anxiety and constant stress development because of his work, and realized that several times, an unconscious centric bruxism occurred during the daytime and, that after sleeping time, he felt pain around his temporo-mandibular joint, mainly, when he was under stress. In the clinical examination, the patient did not present any probing depth $\geq 3 \mathrm{~mm}$ or bleeding on probing, however, an extensive clinical attachment loss ranging from $4 \mathrm{~mm}$ to $7 \mathrm{~mm}$, was verified in the maxilla and the mandible that were principally in the posterior teeth buccal side. The patient presented a satisfactory oral hygiene, no apparent detectable bacterial plaque, calculus, and periodontal inflammation (Fig. 1). A Full-mouth radiographic survey, showed a generalized and horizontal alveolar bone loss, however interproxial bone no present significant loss when compared with bone loss of the buccal side (Fig. 2).
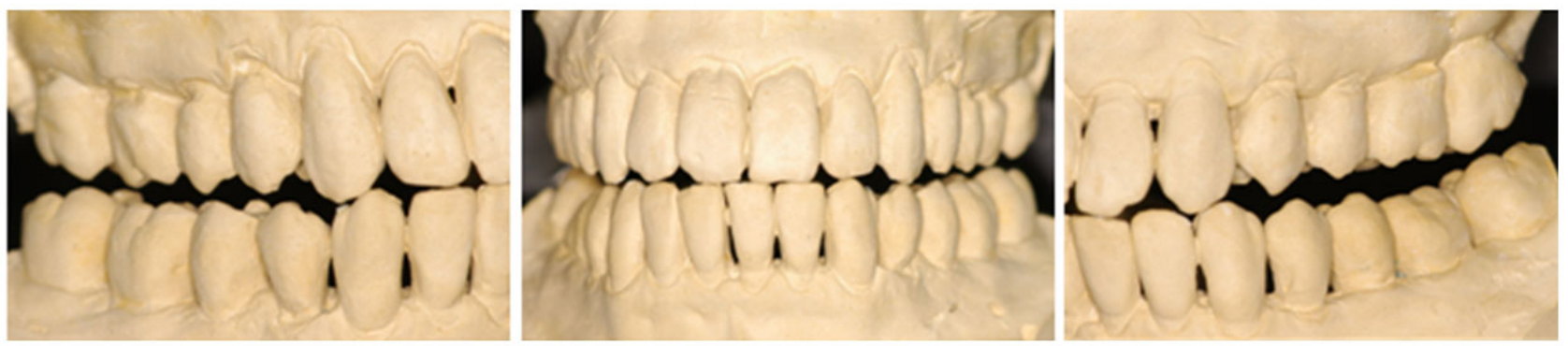

Fig. (3). Anterior guidance influencing the occlusal contour of the posterior teeth.

Results from a complete blood count demonstrated no significant findings. The levels of total hydroxyproline, ALP, calcium, calcitonin, urine calcium, PTH (parathyroid hormone), DHEA (dehydroepiandrosterone), FSH (folliclestimulating hormone), LH (luteinizing hormone), glycemia, total cholesterol, HDL (highdensity lipoprotein), LDL (low-density lipoprotein), triglycerides, type I urine, CRP (C reactive protein) and bone densitometry were completely normal, confirming the findings of previous studies carried out by Repek et al. (2012) [21]. The sub-gingival plaque samples harvested from the sites with the deepest probing depths were, cultured for putative anaerobic periodontal pathogens and analyzed in the commercial Microbiology Testing Laboratory. The samples were negative for Aggregatibacter actinomycetemcomitans, Porphyromonas gingivalis, Bacteroides forsythus, Peptostreptococcus micros, 
Eubacterium sp., Campylobacter rectus, and for enteric the bacteria, while the Fusobacterium sp., and Prevotella intermedia, accounted for $2.0 \%$ and $3.1 \%$ of the flora, respectively. The spirochetes were not observed, using the dark field microscopy. To obtain information about possible previous periodontal infection, blood sample was drawn and serum antibodies titers to antigens of putative periodontal pathogens, were measured using, standard techniques. Titers were not elevated to any of the putative periodontal pathogens tested. Results relative to values for sera from periodontally normal controls set at 100 Enzymes-Linked Immunosorbent Assay (ELISA) units, demonstrated no elevation of titers to antigens of the putative periodontal pathogens tested, and were: A. actinomycetemcomitans $=0 ; \mathrm{P}$. gingivalis $=3$ and $\mathrm{B}$. forsythus $=31$. The data of all the microbiologic analysis, confirm the findings of Page et al . (2002) [20]. The patient was advised to seek psychological treatments, so that he could be able to control his emotional disorder, and, an otorhinolaryngologist to treat his nasal obstruction. Oral hygiene procedures were reviewed, occlusal adjustment and a maxillary night guard were constructed. The patient's protocol control was similar to the one established by Page et al. (2002) [20]. The patient was under professional control every 3 months, however, a treatment plan to treat recession by subepithelial gingival graft was not instituted, since the etiologic factors which induced bone loss and clinical attachment loss, were not well defined. Throughout one year and six months of observation, the patient maintained his teeth, and they were free from significant microbial deposits, as the gingival aspect was reasonably free of inflammation, and the interproximal alveolar bones were stable and without periodontal pocket progression. The results were similar to the results achieved by Page et al. (2002) [20] and Repeke et al. (2012) [21]. However, the loss of the periodontal attachment progress was moderate in the buccal aspect of some teeth, and was predominant in premolars and canines in spite of the treatment instituted. At this time, the patient had difficulty in controlling his emotional disorder under systematic stress.

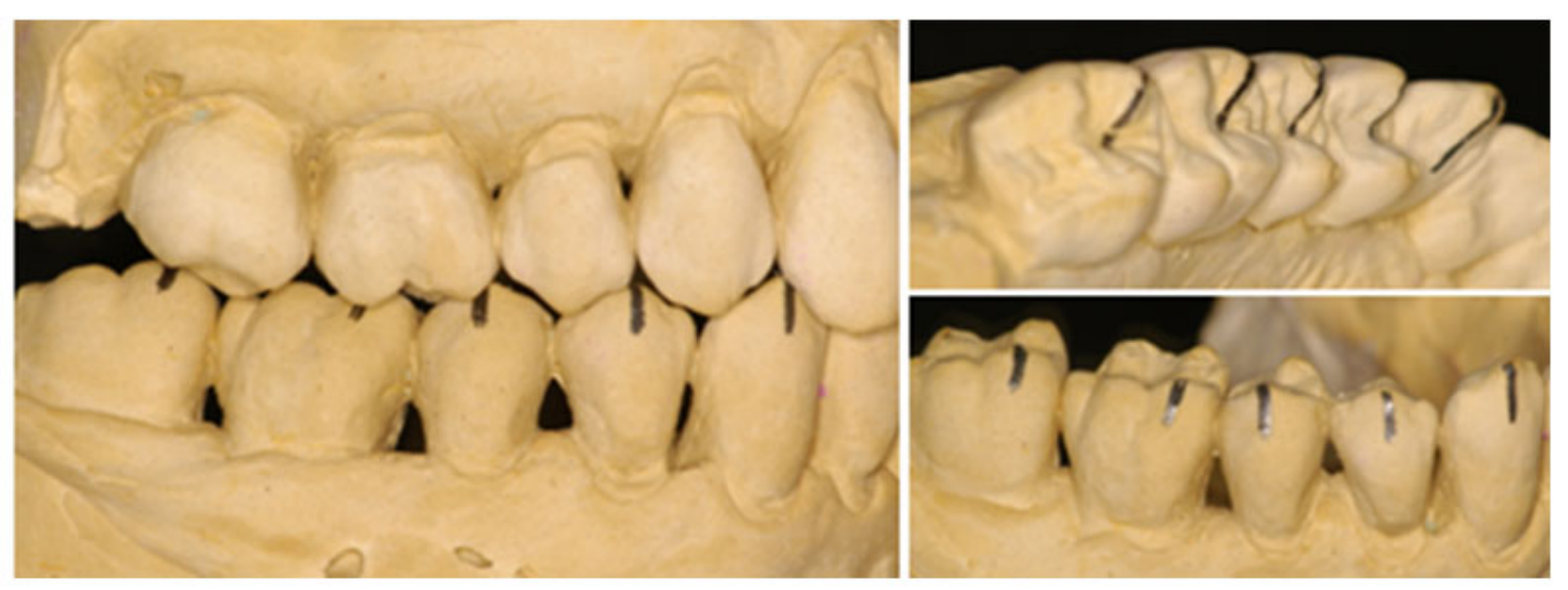

Fig. (4). Posterior teeth high cusps.

\section{DISCUSSION}

In establishing a treatment plan that would be used in treating a disease, it is essential to understand the vital role of the etiological agents that initiated the disease [1 - 16]. The diagnostic of the etiological agents of the periodontal disease is critical, due to the necessity of the association among the various etiological agents, such as bacteria, and several local and/or general predisposing risk factors to induce the disease [1 - 13]. In addition, the destruction produced during the periodontal disease progression, may present similar characteristics, but the association among the bacteria and the various predisposing risk factors, may be distinct and inherent to each person, depending on the host's susceptibility, which does not always present an identical susceptibility to the various local and/or general predisposing risk factors [1 - 19]. Most of the periodontal disease induces local destruction, essentially due to the involvement between the opportunist bacteria and the various and inherent local predisposing risk factors [13]. The local predisposing risk factor may provoke a mechanical vulnerability in the periodontal tissues around a tooth, and/or may assist in bacterial retention, development and organization, in order to originate periodontal tissue destruction [1 - 9, 13]. Generalized periodontal disease may arise, when the systemic predisposing risk factor interferes with the host's defense mechanism against the opportunist bacteria, once the host factor operates in all periodontal tissues [1 - 9, 16 19, 22]. The predisposing risk factor may statistically increase the occurrence of a disease, but it does not cause the 
disease [13]. Predisposing risk factors may be defined as systemic factors, local factors, behavioral factors in nature, and factors related to the development of the acquired alterations that involve the periodontal tissues [7 - 9, 13, 15, 22, 23]. Periodontal disease promote junctional ephitelium ulceration, apical displacement of the gingival attachment, alveolar bone loss and periodontal pocket development, an increase in the depth of gingival sulcus, thereby, creating a favorable anaerobic environment to be infected, as a result of the recurrent contamination by the several species or the combination of the species as exogenous anaerobic and facultative bacteria $[12,13,16,19]$.
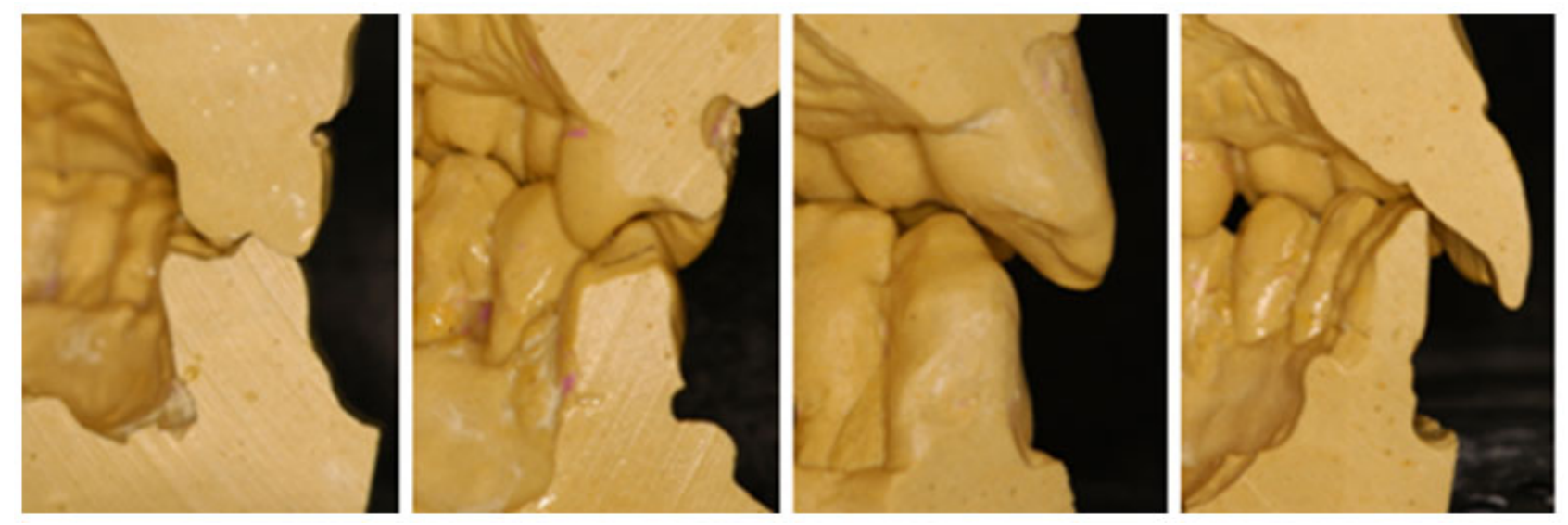

Fig. (5). Relationship between the maxillary and mandibular teeth.

However, not all types of periodontal disease seem to be periodontopathogenic bacteria dependent, and showing pathognomonic signs, as periodontal pocket [19 - 21]. Non-Inflammatory Destructive Periodontal Disease (NIDPD), was defined as a harmful periodontal disease distinguished by the loss of the gingival and periodontal attachment, alveolar bone loss without the detection of a significant level of the periodontopathogenic bacteria, the gingival inflammation or periodontal pocket development [20, 21]. All types of periodontal disease are multifactorial diseases, which progress through successive destructive acute phases, always interposed, by reparative chronic phases [11 - 13]. The indication of the periodontal disease reparative phase, is possible to find in untreated periodontal pocket, as cementum and the gingival-attached connective tissue zone, separating the apical end of the ulcerated periodontal pocket epithelium from the underlying destructed alveolar bone which always presents a repaired cortical bone at a range of levels protecting the cancellous bone [12, 13]. In untreated periodontal disease, the gingival-attached connective tissue zone should be destructed, but they arise most often in untreated periodontal pockets. After each successive destructive acute phase, variations in the quantity and quality of the etiological agents and the predisposing risk factors would arise. However, periodontal diseases always cease at the destructive phase, initiating the reparative phase $[12,13]$. This fact demonstrates that, etiological agents and predisposing risk factors during the periodontal disease progression, acquired better quality and quantity, and could not be able to maintain the periodontal disease destructive phase all the time [13, 23]. Probably, the periodontal disease initiates and progress when at a given time, a specific temporary fragility, assists involved etiological agents in initiating the destructive acute phase of the periodontal disease [13]. One of the transitory predisposing risk factor may be emotional stress, which is intrinsic for each individual, inducing a temporary physical, mental, and functional fragility [24]. The emotional stress, which can emerge from any situation or thought, appears or disappears at any moment, attacks in various aggressive levels, interferes in the host's immune defense, and severely in the stomatognathic system, may possibly be the main predisposing risk factor that can activate or cease the periodontal destruction [3, 13, 24]. Circumstances such as anatomic developmental alterations that affect the periodontium, as teeth presenting high cusps, large crowns and prominent roots, are constant characteristics that were present in the case showed in this paper, and also in recent papers describing NIDPD (Fig. 1, 3-5) [15, 20, 21]. In some situations, these conditions cause functional problems for patients which may affect the periodontal tissues. Every individual with a preserved natural occlusion, presents a premature contact with the centric relation, and is almost impossible to remove all the interfering contacts promoting a stable and permanent artificial condition known as centric occlusion [25]. Some mechanoreceptors from the periodontal ligaments maintain the proprioceptive impulses, by providing feedbacks to avoid occlusal interference [25 - 27]. The stomatognathic system suffers adaptation compensating deleterious premature contact with a habitual occlusion, where a masticatory pattern is developed with the force applied, being dissipated normally in the periodontium [25]. Despite a premature contact, during functional mastication, the antagonist teeth do not establish effective contact. 
However, during daytime and/or sleeping time, the individual under stress may develop centric and/or eccentric bruxism, with the antagonist teeth establishing an effective contact, and generating eccentric and intense forces in the periodontium [28 - 30]. Associated with the teeth high cusps, which can be a predisposing risk factor for centric bruxism, the occlusal forces produced are too excessive to be dissipated by the alveolar bone, mainly in the buccal sides, which are thin due to prominent roots anatomical aspects (Fig. 1, 3-5) [15, 28 - 30]. Then, predisposing risk factors such as emotional stress associated with anatomic developmental alterations and conditions that affect the periodontium, may induce in a specific moment, a local fragility for endogenous opportunist bacteria can establish a rapid transitory acute inflammatory phase, thereby, promoting periodontal destruction [13, 15, 24]. In NIDPD, because of the predisposing risk factors, characteristics and anatomical individuality, the gingival recession arises, instead of periodontal pocket $[20,21]$. Consequently, periodontal pocket an ideal environment to be colonized by exogenous anaerobic periodontophatic bacteria are not produced $[3,13,19]$. This detail could explain the low level or absence of the periodontopathogenic bacteria in NIDPD, and may justify the gingival health appearance in spite of the gingival recession. Furthermore, emotional stress associated with the non-functional distribution of occlusal loads, may also induce areas of excessive force concentration in some teeth, causing them to promote abfraction, a microstructural loss of tooth substance due to microfractures in the enamel with loss of dentine and cementum, creating cavitation adjacent to the gingival region [24, $28-31]$.

Additionally, the mouth breathing condition reported by the patient may also be associated as a predisposing risk factor of NIDPD. Mouth breathing may affect the teeth's position, the lips' resting posture, the tongue's position, and may induce a deviation in the vertical relationship of the maxillary and mandibular dental arches [32, 33]. As each tooth erupts into position within its respective arch, it is guided into a narrow zone, located between horizontally directed forces. The outward pressure of the tongue versus the inward pressure of the perioral musculature, defines a determinant of the occlusion named the neutral zone [34]. The zone of neutrality between these opposing forces, determines the position of each tooth, and establishes the dimensions of the entire arch, including the shape and position of the alveolar process [34]. Individuals with respiratory disorders, such as mouth breathing, may have an abnormal forward tongue posture, in order to enable an adequate airway space that will facilitate breathing [32 - 34]. The abnormally forward tongue posture induces the lack of an outward tongue pressure, against the posterior arch segments [34].

In this situation, the maxillary arch is squeezed inwardly, by the buccinator muscle pressure that is unopposed by the outward tongue pressure [34]. The maxillary arch development becomes altered with a high narrow vault, an abnormal position of the anterior teeth, and the anterior guidance, which may determine bone absence or bone and soft tissue thickness, and the inadequate band of the attached gingiva [32 - 35]. After the mid-palatal suture consolidation, there is no room for the posterior width of the tongue to position itself in a normal posture, so it must be postured forward. The forward tongue posture causes two effects; it evacuates its normal space up in the vault, and it pushes the anterior teeth forward, thereby, causing an intermittent, un-physiologic, and deleterious contact of the tongue with the anterior teeth, which may also cause alveolar bone loss and anterior teeth mobility [32 - 34]. Mouth breathing condition, may also predispose the anterior area to develop periodontal disease, by decreasing salivary flow, since the continuous secretion of saliva provides a flushing action, which aids bacterial control. Saliva also contains antibodies, especially secretory IgA and viable leukocytes derived from the peripheral blood, which are capable of phagocytosis and bacterial killing [32]. To treat a disease, it is fundamental to establish your goals as the elimination and/or the accurate control of all etiologic agents to the lowest levels, which cannot determine disease activity; and/or increase local and/or general resistance against the entire etiologic factors, to promote health in the diseased areas [13]. Although the treatment plan that would have been used in treating gingival recession by subepithelial gingival graft could also increase local resistance due to the keratinized gingival tissue augmentation, the treatment plan was not instituted. The etiologic factors inducing bone loss, clinical attachment loss and gingival recession, all of them sequel of the disease activity were not well defined. Also, the parameters to establish the amount of the keratinized gingival tissue, which could recover exposed dental root surfaces and increase local resistance to supplant all etiologic pathogenic factors, were unable to be defined $[13,35]$. Thus, the opportunist bacteria associated with anatomical aspects, occlusion pattern, emotional stress and mouth breathing, may be associated to the progressive periodontal tissue loss as observed in NIDPD.

\section{CONFLICT OF INTEREST}

The authors confirm that this article content has no conflict of interest. 


\section{ACKNOWLEDGEMENTS}

Declared none.

\section{REFERENCES}

[1] Löe H, Theilade E, Jensen SB. Experimental gingivitis in man. J Periodontol 1965; 36: 177-87. [http://dx.doi.org/10.1902/jop.1965.36.3.177] [PMID: 14296927]

[2] Theilade E, Wright WH, Jensen SB, Löe H. Experimental gingivitis in man. II. A longitudinal clinical and bacteriological investigation. J Periodontal Res 1966; 1: 1-13.

[http://dx.doi.org/10.1111/j.1600-0765.1966.tb01842.x] [PMID: 4224181]

[3] Socransky SS. Relationship of bacteria to the etiology of periodontal disease. J Dent Res 1970; 49(2): 203-22. [http://dx.doi.org/10.1177/00220345700490020401] [PMID: 4313844]

[4] Lindhe J, Hamp S, Löe H. Experimental periodontitis in the beagle dog. J Periodontal Res 1973; 8(1): 1-10. [http://dx.doi.org/10.1111/j.1600-0765.1973.tb00735.x] [PMID: 4272068]

[5] Dzink JL, Socransky SS, Haffajee AD. The predominant cultivable microbiota of active and inactive lesions of destructive periodontal diseases. J Clin Periodontol 1988; 15(5): 316-23. [http://dx.doi.org/10.1111/j.1600-051X.1988.tb01590.x] [PMID: 3292595]

[6] Socransky SS, Haffajee AD. Periodontal microbial ecology. Periodontol 2000 2005; 38: 135-87. [http://dx.doi.org/10.1111/j.1600-0757.2005.00107.x] [PMID: 15853940]

[7] Genco RJ. Current view of risk factors for periodontal diseases. J Periodontol 1996; 67(10): 1041-9. [http://dx.doi.org/10.1902/jop.1996.67.10.1041] [PMID: 8910821]

[8] Pennel BM, Keagle JG. Predisposing factors in the etiology of chronic inflammatory periodontal disease. J Periodontol 1977; 48(9): 517-32. [http://dx.doi.org/10.1902/jop.1977.48.9.517] [PMID: 333086]

[9] Heitz-Mayfield LJ. Disease progression: identification of high-risk groups and individuals for periodontitis. J Clin Periodontol 2005; 32(6)(Suppl. 6): 196-209.

[http://dx.doi.org/10.1111/j.1600-051X.2005.00803.x] [PMID: 16128838]

[10] Goodson JM, Tanner AC, Haffajee AD, Sornberger GC, Socransky SS. Patterns of progression and regression of advanced destructive periodontal disease. J Clin Periodontol 1982; 9(6): 472-81. [http://dx.doi.org/10.1111/j.1600-051X.1982.tb02108.x] [PMID: 6960023]

[11] Socransky SS, Haffajee AD, Goodson JM, Lindhe J. New concepts of destructive periodontal disease. J Clin Periodontol 1984; 11(1): 21-32. [http://dx.doi.org/10.1111/j.1600-051X.1984.tb01305.x] [PMID: 6582072]

[12] Kina JR, Kina J, Kina EF, Kina M, Soubhia AM. Presence of bacteria in dentinal tubules. J Appl Oral Sci 2008; 16(3): 205-8. [http://dx.doi.org/10.1590/S1678-77572008000300008] [PMID: 19089219]

[13] Kina JR, Suzuki TY, Kina J, Kina M, Kina EF. Reparative phase events on periodontal disease progression: interpretation and considerations Int J Microbiol Res 2013; 5(4): 439-44.

[14] Polson AM. Periodontal regeneration: current status and directions. Chicago: Quintessence 1994.

[15] Armitage GC. Periodontal diagnoses and classification of periodontal diseases. Periodontol 2000 2004; 34: 9-21. [http://dx.doi.org/10.1046/j.0906-6713.2002.003421.x] [PMID: 14717852]

[16] Smalley JW. Pathogenic mechanisms in periodontal disease. Adv Dent Res 1994; 8(2): 320-8. [PMID: 7865093]

[17] Dennison DK, Van Dyke TE. The acute inflammatory response and the role of phagocytic cells in periodontal health and disease. Periodontol 2000 1997; 14: 54-78 [http://dx.doi.org/10.1111/j.1600-0757.1997.tb00192.x] [PMID: 9567966]

[18] Craig RG, Yip JK, So MK, Boylan RJ, Socransky SS, Haffajee AD. Relationship of destructive periodontal disease to the acute-phase response. J Periodontol 2003; 74(7): 1007-16. [http://dx.doi.org/10.1902/jop.2003.74.7.1007] [PMID: 12931763]

[19] Takata T, Donath K. The mechanism of pocket formation. A light microscopic study on undecalcified human material. J Periodontol 1988; 59(4): 215-21.

[http://dx.doi.org/10.1902/jop.1988.59.4.215] [PMID: 3164372]

[20] Page RC, Sturdivant EC. Noninflammatory destructive periodontal disease (NDPD). Periodontol 2000 2002; $30: 24-39$. [http://dx.doi.org/10.1034/j.1600-0757.2002.03003.x] [PMID: 12236893]

[21] Repeke CE, Cardoso CR, Claudino M, et al. Non-inflammatory destructive periodontal disease: a clinical, microbiological, immunological and genetic investigation. J Appl Oral Sci 2012; 20(1): 113-21.

[http://dx.doi.org/10.1590/S1678-77572012000100020] [PMID: 22437688]

[22] Schmidt AM, Weidman E, Lalla E, et al. Advanced glycation endproducts (AGEs) induce oxidant stress in the gingiva: a potential mechanism underlying accelerated periodontal disease associated with diabetes. J Periodontal Res 1996; 31(7): 508-15. 
[http://dx.doi.org/10.1111/j.1600-0765.1996.tb01417.x] [PMID: 8915955]

[23] Nyman S, Lindhe J, Ericsson I. The effect of progressive tooth mobility on destructive periodontitis in the dog. J Clin Periodontol 1978; 5(3): 213-25.

[http://dx.doi.org/10.1111/j.1600-051X.1978.tb02282.x] [PMID: 279549]

[24] Rosania AE, Low KG, McCormick CM, Rosania DA. Stress, depression, cortisol, and periodontal disease. J Periodontol 2009; 80(2): 260-6. [http://dx.doi.org/10.1902/jop.2009.080334] [PMID: 19186966]

[25] Dawson PE. Evaluation, diagnosis and treatment of occlusal problems. $2^{\text {nd }}$ ed. St. Louis: Mosby 1989; pp. $72-84$.

[26] Nakanishi H, Seki Y, Kohno T, Muramoto T, Toda K, Soma K. Changes in response properties of periodontal mechanoreceptors after experimental orthodontic tooth movement in rats. Angle Orthod 2004; 74(1): 93-9. [PMID: 15038496]

[27] Naveh GR, Brumfeld V, Shahar R, Weiner S. Tooth periodontal ligament: Direct 3D microCT visualization of the collagen network and how the network changes when the tooth is loaded. J Struct Biol 2013; 181(2): 108-15. [http://dx.doi.org/10.1016/j.jsb.2012.10.008] [PMID: 23110851]

[28] Pavone BW. Bruxism and its effect on the natural teeth. J Prosthet Dent 1985; 53(5): 692-6. [http://dx.doi.org/10.1016/0022-3913(85)90026-5] [PMID: 3858535]

[29] Yustin D, Neff P, Rieger MR, Hurst T. Characterization of 86 bruxing patients with long-term study of their management with occlusal devices and other forms of therapy. J Orofac Pain 1993; 7(1): 54-60. [PMID: 8467297]

[30] Sugimoto K, Yoshimi H, Sasaguri K, Sato S. Occlusion factors influencing the magnitude of sleep bruxism activity. Cranio 2011; 29(2): 127-37. [PMID: 21661587]

[31] Reyes E, Hildebolt C, Langenwalter E, Miley D. Abfractions and attachment loss in teeth with premature contacts in centric relation: clinical observations. J Periodontol 2009; 80(12): 1955-62. [http://dx.doi.org/10.1902/jop.2009.090149] [PMID: 19961379]

[32] Zubery Y, Machtei EE. Advanced periodontal disease and development of anterior open bite. A case report. Am J Dent 1991 ; 4(6): $295-7$. [PMID: 1814352]

[33] Gungor AY, Turkkahraman H. Effects of airway problems on maxillary growth: a review. Eur J Dent 2009; 3(3): 250-4. [PMID: 19756202]

[34] Dawson PE. The neutral zone. In: Evaluation, diagnosis and treatment of occlusal problems. $2^{\text {nd }}$ ed. St. Louis: Mosby 1989 ; pp. $72-84$.

[35] Ericsson I, Lindhe J. Recession in sites with inadequate width of the keratinized gingiva. An experimental study in the dog. J Clin Periodontol 1984; 11(2): 95-103.

[http://dx.doi.org/10.1111/j.1600-051X.1984.tb00837.x] [PMID: 6199377]

Received: December 27, $2014 \quad$ Revised: September 17, 2015

Accepted: October 27, 2015

(C) José Ricardo Kina et al. ; Licensee Bentham Open.

This is an open access article licensed under the terms of the Creative Commons Attribution-Non-Commercial 4.0 International Public License (CC BY-NC 4.0) (https://creativecommons.org/licenses/by-nc/4.0/legalcode), which permits unrestricted, non-commercial use, distribution and reproduction in any medium, provided the work is properly cited. 